\title{
Field measurement and subjects' votes assessment on thermal comfort in high-rise hostels in Malaysia
}

\begin{abstract}
The need to design for low energy consumption dwellings has induced Malaysian architects to design naturally ventilated high-rise hostels $(\mathrm{HH})$, near the capital, Kuala Lumpur. Objective and subjective measurements for thermal comfort investigations were conducted in two high-rise university hostels located in Universiti Malaya, Petaling Jaya (HH1) and Universiti Putra Malaysia, Serdang (HH2) from May 12 to June 19 in 2007. Eighteen rooms located at first, fifth, and top floor of each $\mathrm{HH}$ were measured for different orientations. The measured rooms were naturally ventilated with ceiling fans. Thermal comfort variables were measured prior to the subjective measurement. A total of 208 student occupants responded to the questionnaire. Subjects with 6 months and over living experience in those HH were selected randomly. This study was aimed: (1) to assess the indoor microclimate of each naturally ventilated $\mathrm{HH},(2)$ to identify student occupants' thermal sensation during rainy and clear day, and (3) to simulate the neutral operating temperature for rooms in naturally ventilated high-rise hostels. Findings revealed that room in HH1 which is located on high land and shaded has a more constant operating temperature distribution than rooms in $\mathrm{HH} 2$ that is located on lower land and un-shaded. Operating temperature ranges for $\mathrm{HH} 1$ and $\mathrm{HH} 2$ were $27 ð 31^{\circ} \mathrm{C}$ and $26 \circlearrowright 41^{\circ} \mathrm{C}$, respectively. Results suggested that there is also a possibility that thermal comfort is achievable in shaded naturally ventilated hostels with a window-towall ratio of 0.35 where the internalð external relative humidity is above $70 \% \mathrm{RH}$, especially in south-facing rooms.
\end{abstract}

Keyword: Clear day; Clothing insulation; Operating temperature; PMV; Questionnaire survey; Rainy day; Subjects' thermal sensation vote; Thermal comfort 